\title{
Number and Size Optimizations of Wells Turbine Blades via FEM
}

\author{
[Ibrahim Kutay Yilmazcoban]
}

\begin{abstract}
Wells turbine can be described with the continuous movement of the turbine blades for a mandatory one direction by bidirectional air flow to supply a nonstop electric power. For the present study, finite element simulations were performed after the pilot experimental studies, to optimize the number and size of the blades to evolve the efficiency. Two dissimilar wells blade system was preferred out of three, while different combinations are considered during the numerical approximation. For the diverse air velocities, tangential force and pressure characteristics were evaluated using the numerical fluid dynamics approximation. Eventually, the simulation results were compared with the pilot experiments and concluded with an eligible overlap via satisfactory convergence of the FEM code.
\end{abstract}

Keywords-FEM, turbine blade, optimization, efficiency

\section{Introduction}

Ocean wave energy is one of the renewable forms of energy which can be utilized in response to the disturbing prospect of an exhaustible source of energy. Since ocean wave energy is so conspicuous, many researchers have been inspired to devise methods of converting this energy into more usable forms. Various energy conversion methods have been proposed and one of them is based on the oscillating water column (OWC) system [1,2]. Thomas [3] and Sørensen [4] reviewed the theory behind wave energy convertors. Raghunathan [5,6] presented an extensive review on the performance of the different types of Wells turbines generating energy from oscillating water columns.

The idea behind Wells turbine is to convert the oscillating motion of the wave into bidirectional air flow through the turbine. Sea or ocean waves oscillate up and down in a plenum chamber. The oscillating water surface compresses the air when it moves upward and withdraws air when it moves downward. The free water surface thereby, converts the oscillating wave motion into bidirectional air flow through the Wells turbine. Wells turbine rotor consists of a number of symmetrical airfoil blades [6]. This symmetrical airfoil shape maintains the direction of the tangential force independent of the flow direction. Up to the explained process Wells turbines rotate in the same direction although the bidirectional air flow through the turbine. However, to produce enough energy, powerful waves are needed. Thus, OWC systems are usually used in the oceans or seas that can produce powerful waves. To use wells turbines in other resources, the OWC system should be developed.

Ibrahim Kutay Yilmazcoban

Sakarya University

Turkey
There are too many stages and parameters of energy conversion process in the OWC system. Nevertheless, the performance of turbine plays the most important role, which will give a crucial impact on the overall efficiency. Hence, various parameters which induce the performance of turbine have to be considered properly [7]. Avoiding from the tough experimental conditions, improve the OWC system and also to solve the different parameters in an easy way, computer simulations have been used for a while efficiently in fluid dynamics (CFD) for OWCs. Watterson and Raghunathan [8] studied the effect of solidity on the performance of a Wells turbine with NACA0015 blade profile. The effect of blade geometry with several hub-to-tip ratios and aspect ratios on the performance of a Wells turbine with NACA0020 blade profile was studied by Kim et al. [9]. Dhanasekaran and Govardhan $[6,10]$ presented computational analysis of Wells turbine performance. Raghunathan et al. [11,12] experimentally investigated the effect of inlet turbulence and flow distortion on the performance of monoplane and biplane Wells turbines. They showed that biplane Wells turbines are more sensitive to turbulence compared to monoplane Wells turbines. Mamun et al. [13] and Kinoue et al. [14] experimentally and numerically investigated the hysteretic characteristics of a biplane Wells turbine having zero stagger angles between rotors.

In this study, to improve gaining the energy, different sectioned four and six bladed Wells Turbine (OWC) models were simulated under CFD conditions. After determined which one was more efficient, both of the four and six bladed turbines used as two combinations for biplane wells turbine models.

\section{Numerical Method}

Numerical computations are performed using Ansys/Fluent software to investigate the effect of blade number and shape on Wells turbine performance. A three-dimensional model which is used pressure based solver and implicit formulation developed to simulate airflow over the Wells turbine. The model assumes the air to be incompressible through it passes the turbine. Continuity, momentum, and turbulence equations are solved for airflow in the computational domain.

Turbulence is modeled using the Realizable $\mathrm{k}-\varepsilon$ viscous model which is provided the performance for flows involving rotation, separation, and recirculation [7]. The turbulence airflow model uses two equations in the $\mathrm{k}-\varepsilon$ method, expressed in Eulerian coordinates. The intensity and hydraulic diameter method is used for the turbulent specification method. Turbulent intensity, I, can be represented as

$$
\mathrm{I}=0.16 \operatorname{Re}_{\mathrm{D}}^{-1 / 8}
$$


The non-equilibrium wall function is applied for the nearwall region modeling. The combination of the realizable $\mathrm{k}-\varepsilon$ model and the non-equilibrium wall function enables good prediction of the airflow performance [6]. Moving reference frame (MRF) technique used to model the rotor cycle. The discretization schemes used are standard scheme for pressure, SIMPLEC algorithm for pressure-velocity coupling, and second order scheme for momentum, turbulent kinetic energy, and turbulent dissipation rate.

The mesh structure of the numerical model is shown in Fig. 1. An independent mesh structure study was conducted, where the density of the nodes increased until the solution was no longer changed with additional mesh refinement. Weight factors are used to concentrate the mesh structure near the blade surfaces. Hence, these domains are very important for computational accuracy. Sufficient mesh refinement at the blade surfaces is necessary to capture the wall interaction event and to ensure computational stability. The structured mesh consists of $1,167,741$ elements for 4 blade model and 1008563 for 6 blade model. Full geometry used to model wells turbine, this approach forced to use inconformal mesh structure.

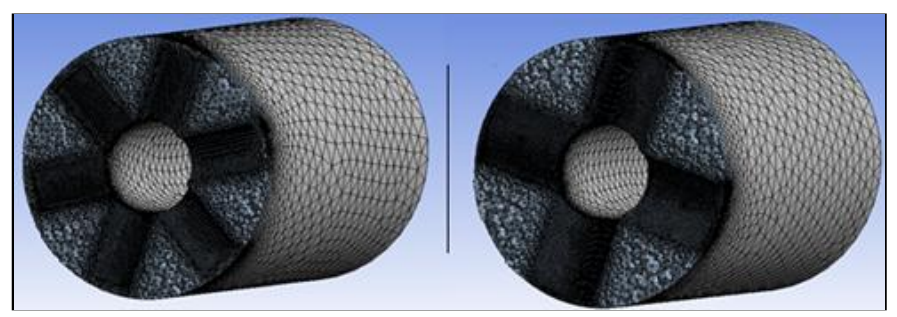

Figure 1. Mesh structure of the model for 6 bladed and 4 bladed Wells turbine.

The boundary conditions for the computational domain are shown in Fig. 2.

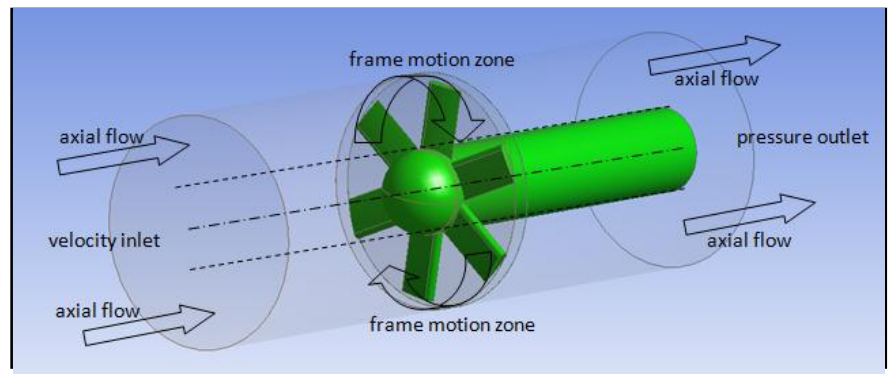

Figure 2. Model boundary conditions

The velocity inlet boundary and pressure outlet boundary, which are normal to axis of Wells turbine, are applied on the inlet and outlet boundaries respectively. The wall boundary conditions are applied at the blades, rotor, and duct surface. Wells turbine is considered to rotate at a constant angular velocity of $600 \mathrm{rpm}$. Uniform velocity is applied at the computational domain velocity inlet. Moving reference frame is applied on the fluid zone which is around the blades. Noslip conditions are used for the Wells turbine blade and hub surfaces. The specification of the turbine model for this study is summarized in Table 1.

TABLE I. SPECIFICATIONS OF THE TURBINE MODEL

\begin{tabular}{|l|c|c|}
\hline \multicolumn{1}{|c|}{ Blade profile } & \multicolumn{2}{|c|}{ Original } \\
\hline Number of blades & 4 & 6 \\
Blade chord length (mm) & 65 & 44 \\
Hub diameter (mm) & 92 & 92 \\
Casing diameter (mm) & 236.22 & 235 \\
Tip clearance (mm) & 5 & 8 \\
\hline
\end{tabular}

Calculations are carried out at different values of flow coefficient $\phi$, which is defined as the ratio of the axial velocity of inlet air flow $v$, to the circumferential velocity of the Wells turbine blade at mean radius $\mathrm{U}$.

$$
\phi=v / \mathrm{U}
$$

The solution is initialized in Hybrid initialization. All under relaxation factors are also kept at their default values through the solution. In order to decide the convergence, the behavior of the total pressure at the pressure outlet boundary, and torque coefficient generated by the rotor are monitored. Eventually, mass balance whose value is $0.359 \%$ for this study is checked to decide the convergence of the solution.

\section{Results and Discussion}

The present work describes the number of blades effects on the wells turbine performance. The turbine performance is expressed in terms of non-dimensional coefficients:

Pressure drop coefficient $\left(\Delta \mathrm{P}_{0}{ }^{*}\right)$

$$
\Delta \mathrm{P}_{0}{ }^{*}=\left(\Delta \mathrm{P}_{0}\right) / \rho \omega^{2} \mathrm{r}^{2}
$$

Where $\Delta \mathrm{P}_{0}$ is the total pressure drop, $\rho$ is the air density, $\omega$ is the angular velocity and $\mathrm{R}$ is the tip radius.

Turbine efficiency $(\eta)$

$$
\eta=(\mathrm{T} \omega) /\left(\Delta \mathrm{P}_{0} \theta\right)
$$

Where $\theta$ is the volume flow rate, and $\mathrm{T}$ is the rotor torque.

Torque coefficient $\left(\mathrm{C}_{\mathrm{T}}\right)$

$$
\mathrm{CT}=\mathrm{T} /\left(\rho \omega^{2} \mathrm{r}^{5}\right)
$$

Analyses are performed at 5 different values of flow coefficient $(\phi) 0.77,0.13,0.26,0.52,0.78$, respectively. Variations of torque coefficient and efficiency with flow coefficient show in Fig. 3 and Fig. 4, respectively. Torque coefficient and efficiency have same tendencies with those explained in Zahari Taha et. al. [1]. Stall point detected at $\phi=$ 0.13 for both two cases. It can be seen in Fig. 4, the efficiency of the turbine decrease a higher value of the flow coefficient increase. Separation takes place on the tip zone of the blade suction side at high values of the flow coefficient. These lead to the turbine to stall. It also interacts with the tip leakage flow and result in substantial decrease of the turbine torque as the blade suction side produces more torque than the pressure side. 


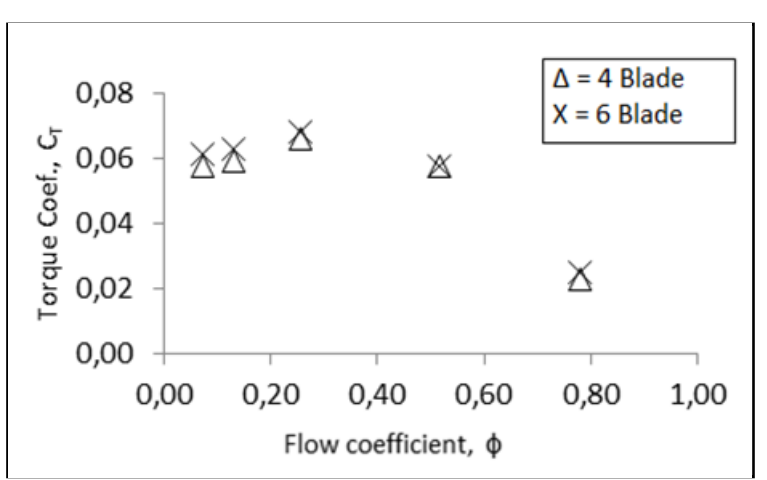

Figure 3. Variation of torque coefficient with flow coefficient

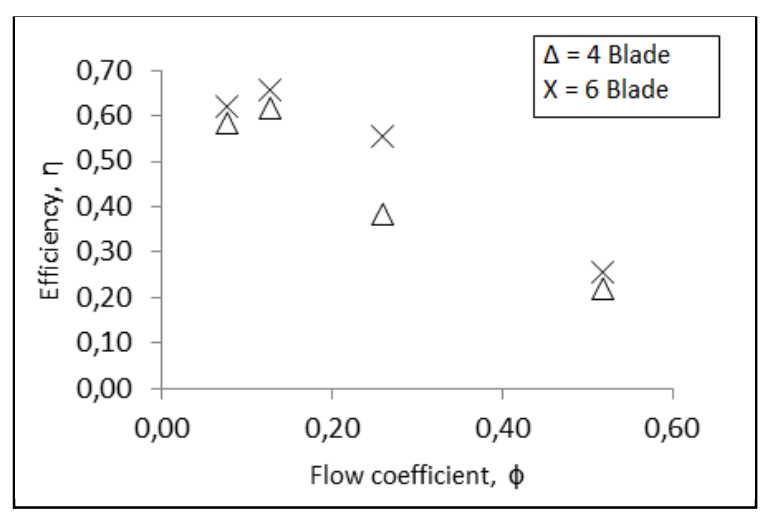

Figure 4. Variation of efficiency with flow coefficient

Therefore, efficiency of the turbine decreases the higher value of the flow coefficient [6]. As a result of Fig. 4, 5 blade turbines is little more effective than 4 blade wells turbine. This shows that number of the blades increase, efficiency of the turbine is increase.

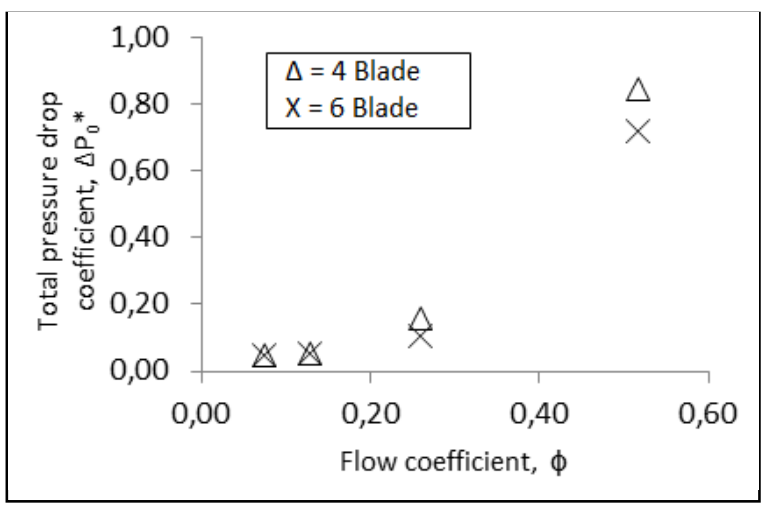

Figure 5. Change of total pressure drop at different flow coefficient

Change of total pressure drop at different flow coefficient shows in Fig. 5. It shows pressure drop coefficient seems very to close at stall point for different blade geometries, and total pressure drop increase with the flow rate increase.

\section{Conclusion}

Numerical studies were conducted to reveal the effect of blade number and shape on Wells turbine performance. A numerical model was developed to simulate the airflow in duct geometry. Change of total pressure drop, torque coefficient, and turbine efficiency were measured at different values of flow coefficient. The major conclusions of the study are:

1. The increase the blade number, the increase the tangential force. This lead to increase the turbine efficiency.

2. Torque coefficient and turbine efficiency have same tendencies with flow coefficient.

3. Torque coefficient and turbine efficiency decrease with flow coefficient increase beyond the stall point.

4. Total pressure drop increase with the flow rate increase.

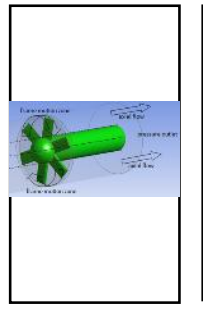

[Wells turbine system is especially advantageous for the waterfront or seaside areas having strong waves and tides to produce free electricity by a continuous motion of the two way rotor blade system.]

\section{Acknowledgment}

I would like to thank the crew for the computational study of fluid dynamics which is performed by C. Yigit and G. Coskun at Mechanical Eng. Department of Sakarya University.

\section{References}

[1] Z. Taha, Sugiyono, and T. Sawada, "A comparison of computational and experimental results of Wells turbine performance for wave energy conversion," Applied Ocean Res., vol. 32, pp. 83-90, 2010.

[2] M.E. Mccormick, Ocean wave energy conversion, Wiley-Interscience, New York, 1981.

[3] T. Gareth, "The theory behind the conversion of ocean wave energy: a review," In: Cruz João, editor. Ocean wave energy: current status and future perspectives. Springer, Berlin Heidelberg, pp 41-91, 2008.

[4] B. Sørensen, "Renewable energy conversion, transmission and storage," Elsevier, 2007.

[5] S. Raghunathan, "The Wells air turbine for wave energy conversion," Prog. Aerosp. Sci., vol. 31, pp. 335-86, 1995.

[6] S. Shaaban, A. Abdel Hafiz, "Effect of duct geometry on Wells turbine performance," Energy Conversion and Management vol. 61, pp. 51-58, 2012

[7] Z. Taha, Sugiyono, T.M.Y.S. Tuan Ya and T. Sawada, "Numerical investigation on the performance of Wells turbine with non-uniform tip clearance for wave energy conversion," Applied Ocean Res., vol. 33, pp. 321-331, 2011.

[8] J.K. Watterson, S. Raghunathan, "Computed effects of solidity on Wells turbine performance," JSME International Journal, Series B., vol. 41(1), pp. 199-205, 1998.

[9] T.H. Kim, T. Setoguchi, Y. Kinoue and K. Kaneko, "Effects of blade geometry on performance of Wells turbine for wave power conversion, "Journal of Thermal Science, vol. 10(4), pp. 293-300, 2001. 
[10] T.S. Dhanasekaran, M. Govardhan, "Computational analysis of performance and flow investigation on well turbine for wave energy conversion, "Renew. Energy, vol. 30, pp. 2129-47, 2005.

[11] S. Shaaban, "Insight analysis of biplane Wells turbine performance," Energy Conversion and Man., vol. 59, pp. 50-57, 2012.

[12] S. Raghunathan, T. Setoguchi and K. Kaneko, "The effect of inlet conditions on the performance of Wells turbine," J Energy Resour. Technol., vol. 111, pp. 37-42, 1989.

[13] M. Mamun, Y. Kinoue, T. Setoguchi, T.H. Kim, K. Kaneko and M. Inoue, "Hysteretic flow characteristics of biplane Wells turbine, "Ocean Eng., vol. 31, pp. 1423-1435, 2004.

[14] Y. Kinoue, T.H. Kim, T. Setoguchi, M. Mamun, K. Kaneko and M. Inoue," Hysteretic characteristics of monoplane and biplane Wells turbine for wave power conversion," Energy Convers. Manage., vol. 45, pp. 1617-29, 2004. 